\title{
LIGHTNING ARRESTERS AND THE PHOTOGRAPHIC STUDY OF SELF-INDUCTION.
}

NOTES ON MR. E. G. ACHESON'S PAPER, BY JOS. STANFORD BROWN AND CHARLES T. CHILD.

Having been requested upon very short notice to re-open the discussion on the highly interesting paper on "Lightning Arresters and the Photographic Study of Self-Induction," presented at the Institute meeting held January 8th, the following hasty notes and queries are with diffidence offered for consideration. Truth alone is sought, and it is a matter of regret if any criticism should even tend to disparage the worthy endeavors of one who has so fearlessly grappled a problem fraught with such interest alike to both theorist and practical electrician.

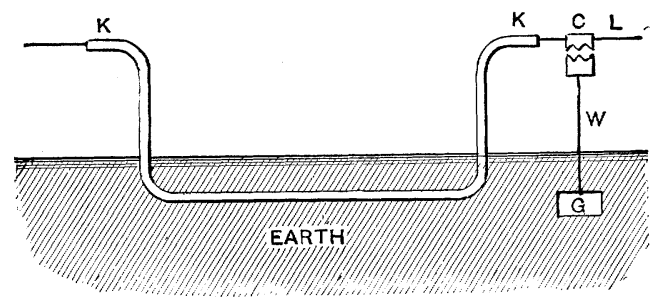

FIG. 1.

After careful reading it would seem as if the subject might be approached with advantage from more than one standpoint, and that even somewhat different conclusions were deducible simply by re-arrangement of the experimental data. We have given, a submarine or subterranean cable, to each end of which at its junction with the main line a lightning arrester is connected in the most approved manner, Fig. 1, to determine why, in spite of these precautions, the cable is not infrequently punctured when an " electrical discharge" enters the overhead system.

For experimental purposes this has been reproduced in miniature, as shown in Figs. $2,2 a, 2 b$ and $2 c$, by the line $\mathrm{L}$ entering the cable $\mathrm{K}$ at the point $\mathrm{P}$, to which point is attached the lightning 
arrester $\mathrm{C}$ grounded through the wire w. The "electrical discharge" arises from the Leyden jar J, charged from the Holtz machine $\mathrm{m} \mathrm{N}$, and strikes the line at $\mathrm{A}$. The outside of $\mathrm{J}$ will represent the earth, to which the ground wire w and the "earthing" of the cable, represented by E, "twisted a single turn" (Western Electrician, IV, 47) about the cable, is connected. Is it not possible, then, to throw Fig. 2 of the previous paper into the form Fig. $2 a$ for the purpose of drawing attention more di-

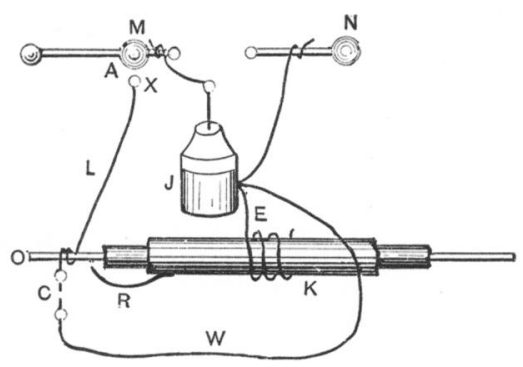

FIG. 2.

$\mathrm{A}$ and $\mathrm{C}$ constant.

$\mathrm{B}$ and $\mathrm{W}$ variable.

Capacity of $\mathrm{J}=.0025 \mathrm{~m}$. $\mathrm{f}$.

" $\mathrm{M}$ and $\mathrm{N}$ not given.

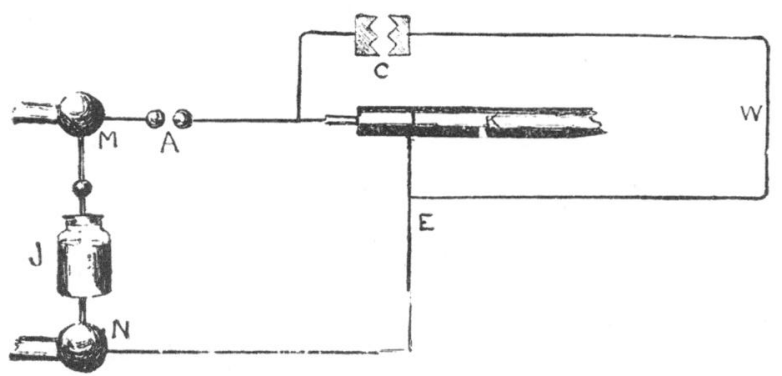

FIG. $2 a$.

Fig. 2 redrawn.

Case of a cable protected by a lightning arrester.

rectly to the relation of the circuits involved? The discharge, or momentary current, from the jar $J$ entering at $\mathrm{A}$ traverses the line $\mathrm{L}$ to the point $\mathrm{P}$, where two paths are offered; one, through the lightning arrester $\hat{\mathrm{c}}$ to earth $\mathbf{E}$; a second, in practice, by puncturing the cable insulation. $\mathrm{C}$ now being made but a fraction of the insulation thickness, and w a short, thick copper wire, it was found that the cable was still frequently punctured at times when a spark appeared at $\mathrm{c}$, and that the length of w appeared to enter 
the effect equally with the space variation of c. No part of the effect, it will be noted, is attributed to the action of the cable as a condenser.

The problem is now changed to that shown in Figs. 3 and 3a, presenting a divided circuit with the lightning arrester at a constant distance of .02 inch, and the earth wire w long, compared with that connecting the variable $\mathrm{B}$ space with the same earth point. May not this arrangement of split circuit with an air space in each branch be looked upon as the general case for which Dr. Lodge's "alternative path" represents the condition of mak-

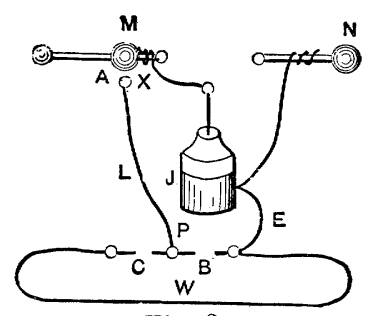

Fig. 3.

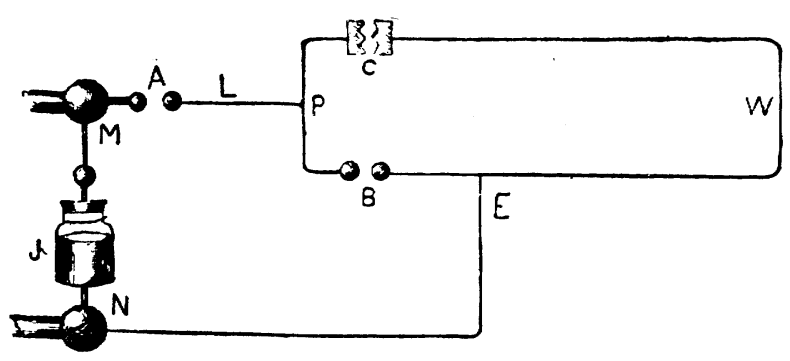

FIG. $3 a$.

Fig. 3 redrawn.

A constant $=0.286 . "$

$C$ " $=0.020 "$

$B$ variable.

$\mathrm{W}$, of copper, .062" diameter, with variable length.

ing one of the air spaces zero? What then is the relative efficacy of changing the length of $\mathrm{w}$ and the distance of the $\mathrm{c}$ points to prevent a spark at $\mathrm{B}$ which represents the puncturing of the cable insulation, providing the в points are held equivalent to the long length of cable wire at any point of which puncturing may occur?

To decide this with $\mathrm{A}$ and $\mathrm{c}$ fixed at .286 and .02 inch, respectively, в was varied with $\mathrm{w}$ to keep the spark ratio of в to A constant at one to ten. Then removing c ( $i$.e., for $\mathrm{c}$ equals zero) the operation was repeated, and a comparison of these results is shown in the curve, Plate A. Instead of this procedure, should not $B$ 
have been made non-sparking for $\mathrm{C}$ and $\mathrm{A}$ fixed, and $\mathrm{w}$ varied until a spark was got at $\mathrm{B}$, and then $\mathrm{w}$ left constant for variations of $\mathrm{c}$ up to a point where $\mathrm{B}$ would spark?

That with the connections of Fig. 4 and w equal 20 feet a spark should pass at $\mathbf{B}$ of over $\frac{1}{3}$ inch in length might perhaps have been expected from Dr. Lodge's results (London Electrician, XXI, 815), shown here in Fig. 4 b, when there is an alternative

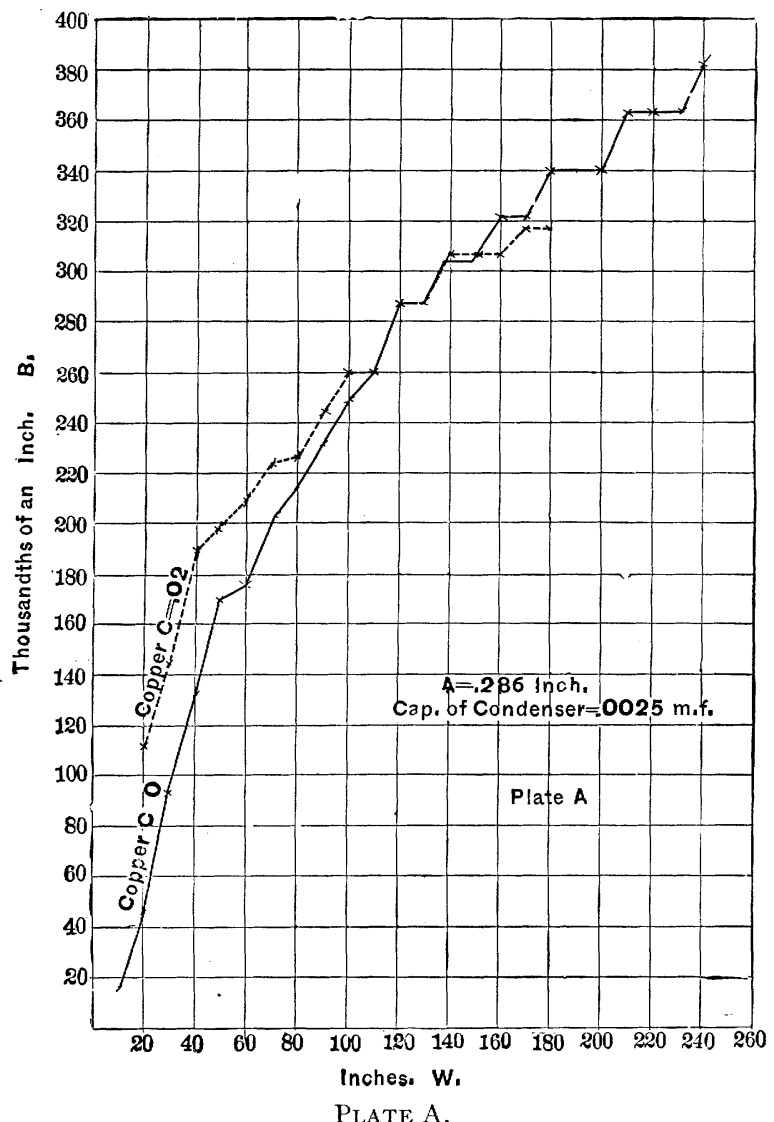

path in which the self-induction of w (Lodge's $\mathrm{L}^{\circ}$ loop) comes into play. True, Fig. 4 is not an "alternative path" of necessity, for the в points may be moved out of the sparking distance.

$\mathrm{W}$ is now supposed "electrified" by the charge across $\mathrm{A}$. The "inverse extra current" of making, simply cuts from the charging current; but the "direct extra current" of breaking, i.e., charging impulse cessation, acts as its continuation but at a higher 
potential (Ganot, 7th edition, 776). This extra current then is running towards $\mathbf{E}$ and would naturally be supposed to equalize on the same path as the current generating it. It might therefore be expected to dissipate on reaching earth; the circuit is, however, claimed to close itself through $\mathbf{P}$ w $\mathrm{E}$ B, or, more cle rrly, around the closed circle of the $\mathrm{L}^{\circ}$ loop, Fig $4 \mathrm{~b}$.

It would be of interest to some in this connection to know how it was ascertained that the instantaneous time duration of the extra current is shorter than that of the charging current; for if

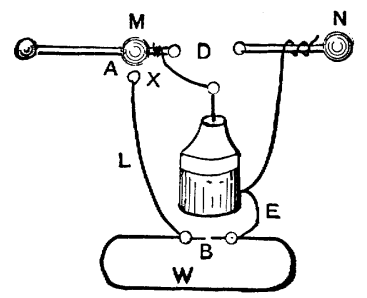

FIG. 4.

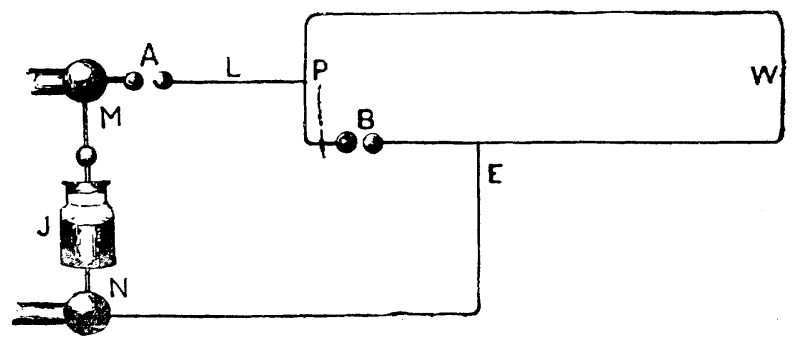

Fig. $4 a$.

A constant $=0.286 . "$

Fig. 4 redrawn.

B " $=0.333 . "$

$\mathrm{C}$ removed.

$\mathrm{W}=20$ feet of copper wire, .052" diameter.

this be assumed, because of the known higher electromotive force of the former, the argument would seem to be in a circle.

On the assumption that the extra current dissipates through $\mathrm{B}$, and not in the earth, it is argued that shortening w would tend to decrease this tendency to puncture the cable. To test this we have $\mathrm{s}$ equal the insulation thickness, $\mathrm{c}$ and $\mathrm{w}$ removed, and we get Fig. $2 \mathrm{~b}$ if the $\mathrm{c}$ w circuit be supposed omitted. "With this arranger.ent it was not found possible to puncture the cable." May not this be regarded simply as a safety short circuit for our cable considered as a Leyden jar? And what is this but a working case of a cable effectually protected by a lightning arrester 
B? While the electrostatic capacity of a "short piece of cable" may be negligible compared with that of twenty feet of No. 16 B. \& S. wire, it is perhaps doubtful if the capacity of a commercial cable could be so regarded in comparison with that of the ground wire from the lightning arrester.

It is not altogether plain how the direct extra current is an effect of Faraday's electro-tonic state when Faraday says (Researches, I, 16): "This state is altogether the effect of induction exerted, and ceases as soon as the inducing force is removed. And Jaquez ("Dictionaire d'Electricité et de Magnetisme," 1887.

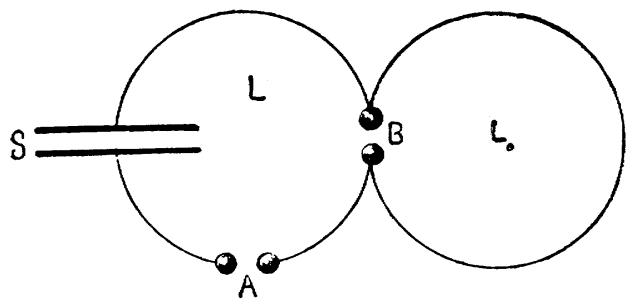

FIG. $4 b$

Cut of Dr. Lodge's Fig. 2, London Electrician (vol. xxi, page 815.) showing alternative path.

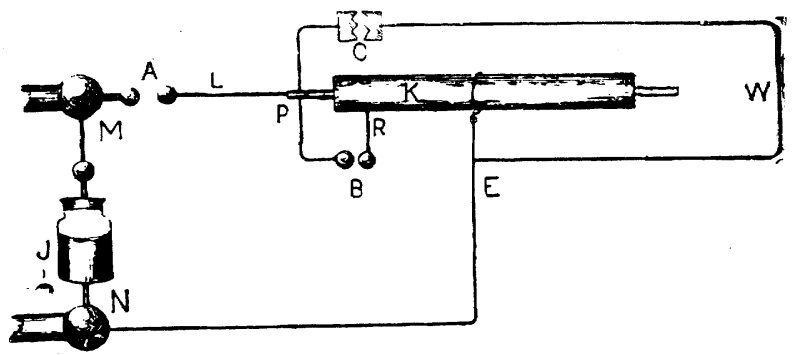

FIG. $2 b$.

p. 138) defines it as "the state of the conductor during the interval of time which separates the appearance and disappearance of an induction current." Maxwell, by the way ["Electricity and Magnetism" (2d ed.) II, 174], calls it " the fundamental quantity in the theory of electro-magnetism." Would it not be possible to regard it as an electro-magnetic potential stored in the wire ready to show itself as direct extra current? With the citations quoted above, how can this electro-tonic state exist before the electrifying current is discharged into the circuit?

Fig. 5, 5a, 6 and 6 a illustrate effects of different kinds of work introduced into the circuit. For references see Fleming's "Short 
Lectures to Electrical Artisans," pp. 44, 45, and Ganot, 7 ed., 776 ; Maxwell, "Electricity and Magnetism," 2d ed., II, 211; Dove, Poggendorff's Annalen, Vol. XLIX, 1840, etc.

The methods used in the photographic part of the investigation would seem to cast some doubt on the results claimed. The effects noted deal chiefly with the prolongation or diminution of the current wave of the jar discharge by the secohmic resistance cut into the circuit. Might not a large element of uncertainty be introduced in the plates by the different degrees of illuminating power possessed by the sparks and by the irradiation of the plate?

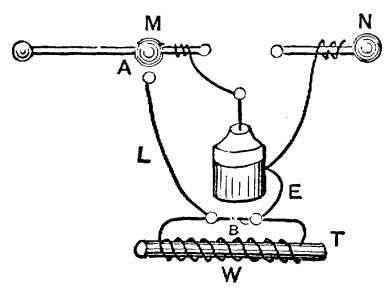

FIG. 5.

$\mathrm{T}=0.25^{\prime \prime}$ diameter.

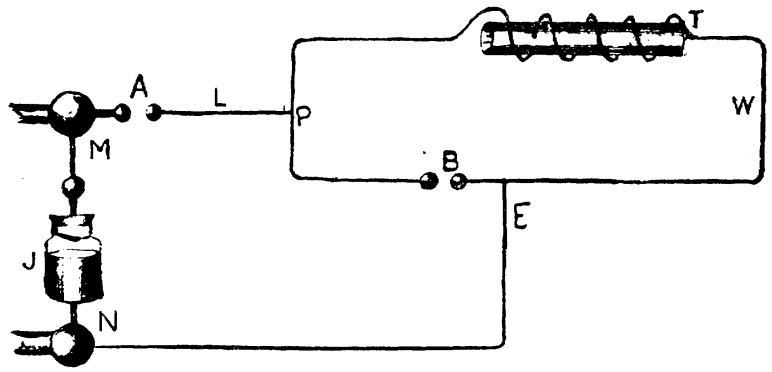

FIG. $5 a$.

Fig. 5 redrawn.

In the cases when the discharges are through 76 and 20 inches of the same wire, respectively, hardly any difference appears in the spark. Is it not possible that the illuminating power of the quick bright spark through the short wire was so much greater than that of the necessarily more extended and consequently fainter spark through the long wire as to make the effect practically the same?

In the experiment in which two spark intervals are included in the circuit, as against one, formerly, it was found that the spark was materially lengthened. This might be expected considering 
the practically infinite resistance of the second air space which is introduced. The spark length, too, was found inversely proportional to any form of work introduced in the ground wire circuit. Possibly the photography of spark duration is not altogether the best method of measuring them. It is not yet by any means certain that a sensitive plate is equally affected by small equal time intervals at the beginning and end of the exposure, nor is it improbable that with sharp edged holes moving at an extremely high velocity some diffraction phenomena might intervene that would introduce serious errors in the photograph. It is, besides, very difficult to measure the faint trails of light left by the spark.

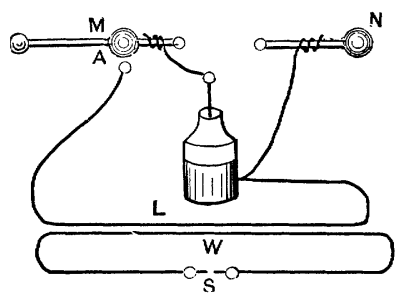

Fig. 6.

Length of parallel portions of circuits, $35^{\prime \prime}$; distance separating them, 0.052."

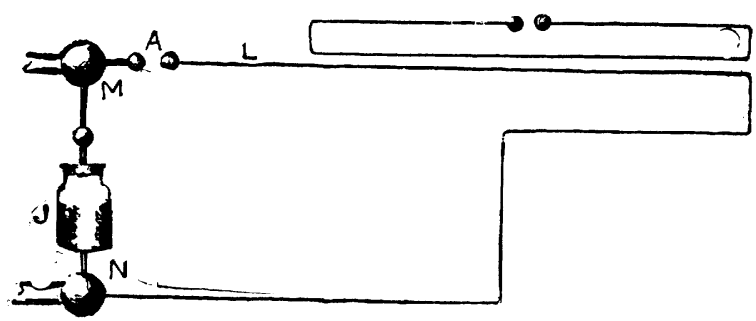

FIG. $6 a$.

Fig. 6 redrawn.

On the negative they are practically invisible and in the prints their extreme delicacy and the fact that they fade away into the surrounding blackness without any sharp line of demarcation renders them almost impossible of measurement. On these grounds the measured spark distances of the first part of the article are probably more trustworthy as a basis for theory than the photographic results of the second part.

Returning to our original problem, why may not the cable, actas a condenser, puncture itself in discharging, it having been charged by the current from A, Fig. 2c, which, meeting the light ning arrester, backs up its potential until able to strike across and 
thus to ground? This discharge occurs simultaneously with the spark at $\mathrm{c}$.

If a wave of current be pictured passing along a linear conductor, it would probably appear something like Fig. 7, its front lengthened out by the self-induction effect of the cable, while the tension in the rear part is raised by the direct extra current. This

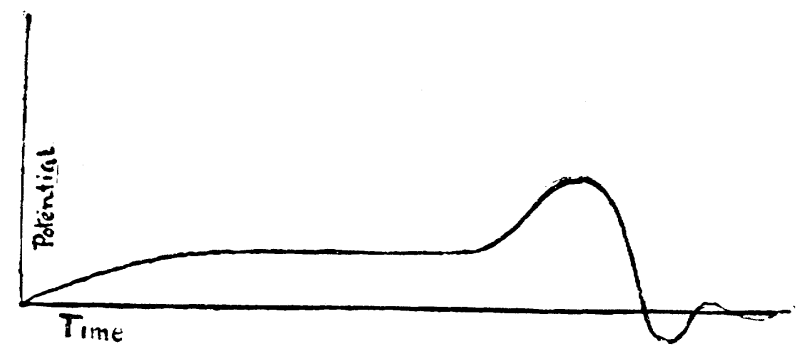

FIG. 7.

Form of current wave

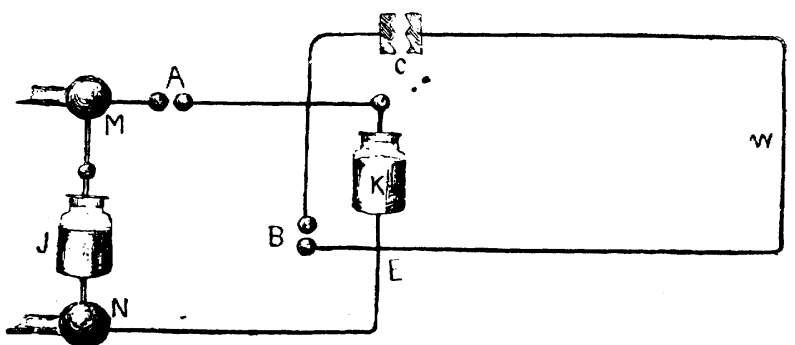

FIG. $2 c$.

Equivalent to Fig. 2, with cable replaced by a condenser.

high potential wave crest moves along the cable, until finding a weak spot in the insulation, it discharges rather than keeps up its strength with the impeding current ahead of it.

It is hoped to be able to present at some future meeting the results of certain experiments delayed so far by pressure of professional engagements.

DISCUSSION.

Mr. Brown:-These points are not meant to be anything in the nature of a discussion of the subject, they are merely brought up as hastily considered, and we hope that some of the gentlemen present may find them worthy of discussion. My friend, $\mathrm{Mr}$. Child, is here, and will be glad to discuss any points, I am sure.

The Chairman:-Gentlemen, these interesting notes are now 
before you for discussion. It is to be regretted that Mr. Acheson is not here, because he is so familiar with the subject that he would have been able to say something of interest in the discussion; however, as the authors promise us a paper at a future meeting, we feel quite certain from the foretaste that they now give us, that the paper will be of great interest. The subject matter of these notes is one that is now receiving a great deal of attention all over the world, particularly in England, on account of its great bearing upon transmission through cables, and more remotely on the effect it has in all underground work. Consequently, it is a matter which is well worthy of study by electrical engineers in general, as well as of specialists.

The Secretary :-I might say that these notes were prepared by these gentlemen with a view of forestalling any criticism which might arise. We felt in talking it over, that if the paper was to be criticised, it would be well to have it done at home, and not abroad, and for that reason the notes were presented in this way, in order that they might be elaborated at some future time. I might say, while I am up, that Mr. Abdank will be pleased to give some information with regard to headquarters which it is proposed to establish at the Paris Exposition. He spoke to me about it, and asked me to do it, but I would like to have him explain it himself, I think he would do it better.

The Chatrman :- If there are no remarks on this paper, we will give the floor to Mr. Abdank.

Mr. Abdank :-We have next year an exposition in Paris, as you know, in which there will be a special section devoted to electricity, and I am in charge of that section for the United States. I have collected a very nice exhibit, and I suggested having in the American section headquarters for the electricians of the United States. We will have there a collection of all the electrical papers published in the United States and the books published here, and then we will have a special attendant there, who will have in charge a register, where the members of the electrical societies can come and find necessary information, and I would suggest that the Institute here give us for the Exposition a collection of the proceedings for its headquarters, and a book wherein the members of the society arriving in Paris may inscribe their names.

The Chairman:-We are very grateful for these remarks; the plan is one that every electrician will appreciate who visits the Exposition. 
Mr. Abdank:-I forgot one thing, we have a special box for the reception of letters addressed to members, and any member intending to visit the Exposition can have his letters delivered there by simply having them addressed to the Paris Exposition, American Section, Box Electric. Our office boy will put all the letters in order, and we will distribute them to the members arriving in Paris.

The Secretary :-The Council, as you are probably aware, has arranged to supply a set of Transactions to the Exposition, and I presume they will act on Mr. Abdank's suggestion and furnish a register for the recording of names.

The Charrman:-I have no doubt that the subject will be taken up in due course by the proper authorities, and that our secretary here, with his usual eye to everything relating to the welfare of the Institute, will see that the matter is attended to in the proper manner.

Adjourned. 